\title{
Questes
}

vestes Revue pluridisciplinaire d'études médiévales

$23 \mid 2012$

Le doute

\section{Le doute : éléments bibliographiques}

\section{Servane Michel et Francesco Montorsi}

\section{(2) OpenEdition}

\section{Journals}

Édition électronique

URL : http://journals.openedition.org/questes/855

DOI : 10.4000/questes.855

ISSN : 2109-9472

\section{Éditeur}

Les Amis de Questes

\section{Édition imprimée}

Date de publication : 15 mars 2012

Pagination : 137-139

ISSN : 2102-7188

\section{Référence électronique}

Servane Michel et Francesco Montorsi, «Le doute : éléments bibliographiques », Questes [En ligne], 23 | 2012, mis en ligne le 01 janvier 2014, consulté le 15 septembre 2020. URL : http:// journals.openedition.org/questes/855 


\section{Éléments bibliographiques}

\section{Scepticisme médiéval}

Boureau, Alain, «L'individu, sujet de la vérité et suppôt de l'erreur. Connaissance et dissidence dans le monde scolastique (vers 1270-vers 1330) », in Brigitte Miriam Bedos-RezaK et Dominique IognA-Prat (éd.), L'Individu au Moyen Âge. Individuation et individualisation avant la modernité, Paris, Aubier, 2005, p. 289-306.

BOYARD, Charles, entrée «Medieval Skepticism », in Edward N. ZALTA (éd.), The Stanford Encyclopedia of Philosophy (Winter 2010 Edition), http://plato.stanford.edu/archives/win2010/entries/skepticism-medieval/ (une bibliographie abondante donne les sources médiévales et les travaux critiques les plus récents).

Flanagan, Sabina, Doubt in an Age of Faith : Uncertainty in the Long Twelfth Century, Turnhout, Brepols, « Disputatio », 17, 2008.

Flanagan, Sabina, "Lexicographic and Syntactic Explorations of Doubt in Twelfth-Century Latin Texts », Journal of Medieval History, 27 (2001), p. 219-240.

GRELlaRd, Christophe, «Comment peut-on se fier à l'expérience ? Esquisse d'une typologie des réponses médiévales au scepticisme », Quaestio, 4 (2004), p. 113-135.

GRELlARD, Christophe, «Jean de Salisbury. Un cas médiéval de scepticisme », Freiburg Zeitschrift für Theologie und Philosophie, 54 (2007), p. 16-40.

HisseTte, Roland, Enquête sur les 219 articles condamnés à Paris le 7 mars 1277, Louvain/Paris, Publications universitaires/Vander-Oyez, «Philosophes médiévaux », 22, 1977.

REYNOLDS, Susan, «Social Mentalities and the Case of Medieval Scepticism », Transactions of the Royal Historical Society, Sixth series, 1 (1991), p. 26-27.

RIJK, Lambertus Marie de, La Philosophie médiévale, Leyde, E. J. Brill, 1985, chap. «Scepticisme antique et criticisme médiéval », p. 204-218.

\section{Incroyance}

Anticlericalism in Late Medieval and Early Modern Europe, Peter A. DYKEMA et Heiko A. Oberman (éd.), Leyde/New York/Cologne, E. J. Brill, «Studies in Medieval and Reformation Thought », 51, 1993.

ARNOLD, John H., Belief and Unbelief in Medieval Europe, Londres, Hodder Arnold, 2005. 
Atheismus im Mittelalter und in der Renaissance, Friedrich NIEWÖHNER et Olaf PluTA (dir.), Wiesbaden, Harrassowitz Verlag, «Wolfenbütteler MittelalterStudien », 12, 1999.

BAKHTINE, Mikhaïl, L'CEuvre de François Rabelais et la culture populaire au Moyen Âge et sous la Renaissance, André RoBel (trad.), Paris, Gallimard, «Bibliothèque des Idées », 1970 ( $1^{\text {ère }}$ éd. russe 1965).

CANnuyer, Christian, «Des incroyants au Moyen Âge? », Mélanges de science religieuse, 63, 3 (2006), p. 21-32.

DinZELBACHER, Peter, «Étude sur l'incroyance à l'époque de la foi », Revue des sciences religieuses, 73, 1 (1999), p. 42-79.

DINZELBACHER, Peter, Unglaube im «Zeitalter des Glaubens». Atheismus und Skeptizismus im Mittelalter, Badenweiler, Wissenschaftlicher Verlag Bachmann, 2009.

ESPOSITO, Mario, «Una manifestazione d'incredulità religiosa nel medioevo : il detto dei "Tre impostori" e la sua trasmissione da Federico II a Pomponazzi », Archivio storico Italiano, 16 (1931), p. 3-48.

FEBVRE, Lucien, Le Problème de l'incroyance au XVI siècle. La religion de Rabelais, Paris, Albin Michel, «L'Évolution de l'humanité », 3, 1947.

GinZBURG, Carlo, Le Fromage et les vers. L'univers d'un meunier du XVI siècle, Monique AYMARD (trad.), Paris, Flammarion, "Nouvelle bibliothèque scientifique », 1980 (Il formaggio e $i$ vermi. Il cosmo di un mugnaio del '500, $1^{\text {ère }}$ éd. italienne 1976).

Golinelli, Paolo, Città e culto dei santi nel Medioevo italiano, Bologne, Clueb, «Biblioteca di storia urbana e medievale», 4 bis, 1996, chap. «Il santo gabbato : forme di incredulità nel mondo cittadino italiano », p. 103-130.

Golinelli, Paolo, Il Medioevo degli increduli. Miscredenti, beffatori, anticlericali, Milan, Mursia, «Storia, biografie, diari », 2009.

GolinelLI, Paolo, «Il topos dell'incredulo punito nell'agiografia padana dei secoli IX-XII », in Domenico GoBBI (dir.), Florentissima proles Ecclesiae. Miscellanea hagiographica, historica et liturgica Reginaldo Grégoire O.S.B. XII lustra complenti oblata, Trento, Civis, «Biblioteca Civis », 9, 1996, p. 305-325.

Goodich, Michael, «Miracles and Disbelief in the Late Middle Ages », Mediaevistik, 1 (1988), p. 23-38.

Goodich, Michael, Miracles and Wonders. The Development of the Concept of Miracle, 1150-1350, Aldershot, Ashgate, "Church, Faith and Culture in the Medieval West », 2007.

Justice, Steven, «Did the Middle Ages Believe in Their Miracles?», Representations, 103, 1 (2008), p. 1-29. 
The Pagan Middle Ages, Ludo Jr. MiLIs (dir.), Tanis Guest (trad.), WoodbridgeRochester, The Boydell Press, 1999 (De heidense Middeleeuwen, $1^{\text {ère }}$ éd. belge 1991).

MinoIs, Georges, Histoire de l'athéisme. Les incroyants dans le monde occidental des origines à nos jours, Paris, Fayard, 1998, chap. «Un athéisme médiéval ?», p. 68-104.

MurraY, Alexander, «Piety and Impiety in Thirteenth-Century Italy », Studies in Church History, 8 (1972), p. 83-106.

SCHMITT, Jean-Claude, «La croyance au Moyen Âge », Raison présente, 113 (1995), p. 5-22.

SCHREINER, Klaus, "Gab es im Mittelalter und in der frühen Neuzeit Antiklerikalismus? Von der Schwierigkeit, aus einem modernen Kampbegriff eine Kategorie historischer Erkenntnis zu machen », Zeitschrift für Historische Forschung, 21 (1994), p. 513-521.

SigAL, Pierre André, L'Homme et le miracle dans la France médiévale. XI $-X I I^{e}$ siècles, Paris, Éditions du Cerf, « Cerf-Histoire », 11, 1985.

TOUSSAERT, Jacques, Le Sentiment religieux en Flandre à la fin du Moyen Âge, Paris, Plon «Civilisations d'hier et aujourd'hui », 1963.

WIRTH, Jean, «Naissance du concept de croyance (XII - XVII ${ }^{\mathrm{e}}$ siècles) », Bibliothèque d'Humanisme et Renaissance, 45 (1983), p. 7-58.

WIRTH, Jean, Sainte Anne est une sorcière. Et autres essais, Genève, Droz, «Titre courant », 26, 2003.

\section{III. « Doubting Thomas »}

Bonney, William, Caused to Believe. The Doubting Thomas Story at the Climax of John's Christological Narrative, Leyde/Boston, E. J. Brill, «Biblical Interpretation Series », 62, 2002.

CoBB, John B., Thomas pris de doute, Pierre-Yves RuFF (trad.), Paris, Van Dieren, «La Bibliothèque de Théolib », 1999 (Doubting Thomas. Christology in Story Form, 1 ère éd. américaine 1992).

Most, Glenn W., Thomas l'incrédule, Isabelle WIENAND (trad.), Paris, Le FélinKiron, «L'Autre scène », 2009 (Doubting Thomas, $1^{\text {ère }}$ éd. américaine 2005).

Murray, Alexander, Doubting Thomas in Medieval Exegesis and Art, Rome, Unione internazionale degli istituti di archeologia storia e storia dell'arte in Roma, Rome, 2006. 